\title{
Effects of Dietary Oil Supplementation with Different Fatty Acid Profiles on Rumen Fibre Degrading Bacteria Population in Goats
}

\author{
Ibrahim $\mathrm{NA}^{1,2}$, Alimon $\mathrm{AR}^{2,3}$, Yaakub $\mathrm{H}^{3}$, Abdullah $\mathrm{N}^{2}$, Samsudin $\mathrm{AA}^{2,3 *}$ \\ ${ }^{1}$ Malaysian Palm Oil Board \\ ${ }^{2}$ Institute of Tropical Agriculture, Universiti Putra Malaysia, 43400 UPM Serdang, Selangor, Malaysia \\ ${ }^{3}$ Department of Animal Science, Universiti Putra Malaysia, 43400 UPM Serdang, Selangor, Malaysia \\ anjas@upm.edu.my
}

\begin{abstract}
Effects of dietary oil supplementation on the predominant rumen fibre-degrading bacteria population were investigated. In this experiment, rumen fibre-degrading bacteria population were evaluated on 16 fistulated male goats that were randomly assigned to four treatment groups: T1: control/basal diet (CNT); T2: basal diet + olive oil (OL); T3: basal diet + palm olein oil (PO); and T4: basal diet + sunflower oil (SF). The oil content was supplemented at $6 \%$ of DM bases. Rumen content was collected from each individual animal and the DNA was extracted accordingly. The number of rumen fibre-degrading bacteria was enumerated via real-time PCR method. Significant difference $(\mathrm{P}<0.05)$ were observed for Ruminococcus albus in supplemented diet as compared to T1. The other two fibre-degrading bacteria, Fibrobacter succinogenes and R. flavefaciens were not highly affected by the supplementation of the dietary oils. This study has demonstrated that supplementation of dietary oils with differing fatty acid components has no impact on the predominant rumen fibre-degrading bacteria which benefit the animals by providing extra energy from the dietary oil supplementation without compromising the ability of rumen fibre digestion process.
\end{abstract}

Key Words: Dietary Oil, Supplementation, Rumen, Fibre-Degrading Bacteria, PCR

\section{INTRODUCTION}

In ruminants, nutrients such as protein and carbohydrates are mostly fermented by rumen microorganism. During this process, the end products of fermentation such as $\mathrm{CO}_{2}$, methane and VFA are vital in providing the host with nutrients. Apart from that, lactate, hydrogen and succinate were also produced, but these compounds are rapidly utilized by certain microbial species in the rumen. Animal nutritionists have been working on improving the nutrients of ruminants by manipulating the rumen microbial ecosystem to enhance fibrous feed digestibility, reducing methane emission and reducing the nitrogen excretion by ruminant (Wanapat \& Pilajun 2011). Supplementation of vegetable oil containing medium-chain fatty acids are known to have a negative effects on the predominant rumen fibre-degrading bacteria population. The effects of the dietary oils on the rumen microbial populations are highly depending on their fatty acid compositions and the degree of saturation. Unsaturated fatty acids are more toxic and can inhibit fermentation in the rumen more predominantly than the saturated fatty acids (Jenkins 1993). In recent years some oilseeds crops have been genetically modified to produce high concentration of one of the $\mathrm{C}_{18}$ fatty acids such as oleic (C18:1), linoleic (C18:2) or linolenic (C18:3) acid in the oil. The C18:2 and C18:3 fatty acids are known to be beneficial to rumen fibre-degrading bacteria, in particular the dietary linoleic acid which has increased the concentration of total fibre-degrading bacteria species in the rumen by over $80 \%$. To our knowledge, there is not much information available that emphasizes on the effect of diets supplemented with locally produced such as palm olein oil that contain the combination of $\mathrm{C} 18: 1$ and palmitic acid $(\mathrm{C} 16: 0)$ on the predominant rumen fibre- 
degrading bacteria population in goats. Therefore the aim of this study was to investigate the predominant rumen fibre-degrading bacteria population of local goats fed with diets supplemented with either sunflower oil (SFO), olive oil (OO), or palm olein oil (POO).

\section{MATERIAL AND METHODS}

\section{Animal and diet}

Sixteen local crossed goats aged between 20-24 months with average body weight of $25 \mathrm{~kg}$ fitted with rumen cannulae were randomly assigned according to a complete randomized design. The animals were subjected to four dietary diets as follow: T1 (basal diet); T2 (basal diet + olive oil); T3 (basal diet + palm olein oil); T4 (basal diet + sunflower oil). T1 acted as a control group, whereas the other groups were supplemented with $6 \%$ of DM bases of the stated oils that were obtained from commercial sources. The diets were formulated to meet maintenance requirement for adult goats in accordance with the guideline of nutrient requirements of small ruminants (NRC 1981) and to give approximately equal crude protein (CP) content of $15-16 \%$, as presented in Table 1 . The goats were kept individually in separated pens. The diets were offered ad libitum to the goats at 09:00 h daily and have free access to water.

Table 1. Ingredient and chemical composition of experimental diets

\begin{tabular}{|c|c|c|c|c|}
\hline \multirow{2}{*}{ Ingredient $(\mathrm{g} / \mathrm{kg} \mathrm{DM})$} & \multicolumn{4}{|c|}{ Treatments } \\
\hline & T1: CNT & T2: OL & T3: PO & T4: SF \\
\hline Rice straw & 350 & 308 & 308 & 308 \\
\hline Barley grain & 350 & 350 & 350 & 350 \\
\hline Soybean meal & 300 & 300 & 300 & 300 \\
\hline Molases & 30 & 20 & 20 & 20 \\
\hline Vitamin mineral-mix & 5 & 5 & 5 & 5 \\
\hline Limestone & 13 & 13 & 13 & 13 \\
\hline Sodium sulphate & 4 & 4 & 4 & 4 \\
\hline Olive oil & - & 6 & - & - \\
\hline Palm olein oil & - & - & 6 & - \\
\hline Sunflower oil & - & - & - & 6 \\
\hline \multicolumn{5}{|c|}{ Chemical analysis (DM \%) } \\
\hline $\mathrm{DM}$ & 76.17 & 76.02 & 78.27 & 78.73 \\
\hline $\mathrm{OM}$ & 93.60 & 93.34 & 94.61 & 94.96 \\
\hline $\mathrm{CP}$ & 15.76 & 15.48 & 15.90 & 16.00 \\
\hline $\mathrm{EE}$ & 1.86 & 4.56 & 4.70 & 4.74 \\
\hline NDF & 63.53 & 58.76 & 58.54 & 51.27 \\
\hline $\mathrm{ADF}$ & 17.04 & 18.26 & 20.66 & 21.41 \\
\hline
\end{tabular}

CNT: Basal diet; OL: basal diet + Olive oil; PO: basal diet + Palm olein; SF: basal diet + Sunflower oil; DM: Dry matter; OM: Organic matter; CP: Crude protein; EE: Ether extract; NDF: Neutral detergent fiber; ADF: Acid detergent fiber 


\section{DNA extraction and quantification using qPCR}

Total genomic from rumen content samples was extracted using QIAamp DNA Stool Mini Kit (Qiagen Inc., Valencia, CA, USA). The guideline of the protocol was provided by the manufacturer. The extracted DNA was stored at $-20^{\circ} \mathrm{C}$ until the subsequent procedures. Real-time PCR was used to determine the population of the Fibrobacter succinogens, Ruminococcus albus, and Ruminococcus flavefaciens. Species-specific PCR primers used to amplify partial $16 \mathrm{~S}$ rDNA regions were chosen from literatures as presented in Table 2. Real-time PCR amplification and detection were performed using CFX 96 system (Bio$\mathrm{Rad}$, Hercules, CA, USA). The amplification reaction was conducted in a final volume of $25 \mu \mathrm{l}$ containing the following: $12.5 \mu \mathrm{l}$ Maxima SYBR Green qPCR Master Mix, $1 \mu \mathrm{l}$ species-specific PCR forward primer, $1 \mu \mathrm{l}$ species-specific PCR reverse primer, $8.5 \mu \mathrm{l}$ RNAse free distilled water, and $2 \mu \mathrm{l}$ of DNA elution. PCR conditions of all species were as follows: $15 \mathrm{~s}$ at $95^{\circ} \mathrm{C}$ for denaturing, 30s at annealing temperature, $20 \mathrm{~s}$ at $72^{\circ} \mathrm{C}$ for an extension for 39 cycles. The standards used in this study were prepared according protocol demonstrated by Navidshad et al. (2012).

Table 2. The PCR primer used for quantification of rumen microorganism

\begin{tabular}{|c|c|c|c|c|}
\hline \multirow{2}{*}{ Microbes } & \multicolumn{2}{|c|}{ Primer } & \multirow{2}{*}{$\begin{array}{l}\text { Amplicon } \\
\text { (base pairs) }\end{array}$} & \multirow{2}{*}{ Ref } \\
\hline & Forward & Reverse & & \\
\hline $\begin{array}{l}\text { Fibrobacter } \\
\text { succinogenes }\end{array}$ & $\begin{array}{l}\text { 5'GTTCGGAATTACTG } \\
\text { GGCGTAAA-3' }\end{array}$ & $\begin{array}{l}\text { 5'CGCCTGCCCC } \\
\text { TGAACTATC-3' }\end{array}$ & 121 & 1,2 \\
\hline $\begin{array}{l}\text { Ruminococcus } \\
\text { albus }\end{array}$ & $\begin{array}{l}\text { 5'-CCC TAA AAG CAG } \\
\text { TCT TAG TTC G-3' }\end{array}$ & $\begin{array}{l}\text { 5'-CCT CCT TGC } \\
\text { GGT TAG AAC } \\
\text { A3' }\end{array}$ & 175 & 3 \\
\hline $\begin{array}{l}\text { Ruminococcus } \\
\text { flavefaciens }\end{array}$ & $\begin{array}{l}\text { 5'CGAACGGAGATAA } \\
\text { TTTGAGTTTACTTAG } \\
\text { G-3' }\end{array}$ & $\begin{array}{l}\text { 5'CGGTCTCTGT } \\
\text { ATGTTATGAGG } \\
\text { TATTACC-3' }\end{array}$ & 132 & 1,2 \\
\hline
\end{tabular}

Source: ${ }^{1}$ Samsudin et al. (2014); ${ }^{2}$ Denman \& McSweeney $(2006) ;{ }^{3}$ Koike \& Kobayashi $(2001)$

\section{Statistical analysis}

The data were statistically analyzed using general linear model (GLM) procedure and Duncan Multiple Range Test was used to further compare means at $\mathrm{P}<0.05$.

\section{RESULTS AND DISCUSSION}

The effects of dietary oils on rumen microbial population are presented in Table 3. High number of total bacteria populations can be observed in the treatment groups compared to CNT, although it is not statistically significant $(\mathrm{P}>0.05)$. No significant difference was also observed in the $F$. succinogenes population. Significant differences $(\mathrm{P}<0.05)$ were observed for $R$. albus population, and the number is highly influenced by treatment, day of sampling and the interaction of treatmentxday. On the other hand, $R$. flavefaciens show numerically higher in the treatment groups compared with CNT and differ significantly $(\mathrm{P}<0.05)$ by interaction of treatment $\times$ day among groups. Different responses of fatty acid supplementation on the predominant fibre-degrading rumen bacteria are shown in the present study. High number of $F$. succinogenes recorded in OL (C18:1), R. flavefaciens in the all of the supplemented diet; and significant increase of $R$. 
albus in the PO and SF groups compared to CNT may suggest that fatty acid does not have any direct effect on the ruminal microbial population. It seems possible that rumen microbial population were influenced by the population of protozoa instead of fatty acid supplementation. These findings further support the idea of Ivan et al. (2013) that observed an inhibitory effect of certain fatty acid towards $F$. succinogens, but the population of $R$. albus and $R$. flavefaciens was increased. It was also shown additional dietary $\mathrm{C}_{18}$ fatty an acid does not affect the total rumen bacteria population. Another possible reason was mentioned by Yabuuchi et al. (2007) that reported the negative effects towards ruminal fibrolytic bacteria were neglected in the case of high grain feed diet. In their study, neither NDF nor fibrolytic bacteria population has shown significant responses towards fatty acid supplementation. Thus, it was hypotheses that the increment of measured cellulolytic bacteria in the rumen is due to the forfeit of other bacterial populations.

Table 3. Effects of supplementation with different types of oils on microbial population in the rumen of goats

\begin{tabular}{llcccl}
\hline \hline \multirow{2}{*}{ Parameter } & \multicolumn{5}{c}{ Treatment } \\
\cline { 2 - 6 } & T1: CNT & T2: OL & T3: PO & T4: SF & Sig \\
\hline F. succinogenes $\left(\times 10^{4} / \mathrm{ml}\right)$ & $6.040 \pm 2.110$ & $8.600 \pm 7.800$ & $4.730 \pm 1.230$ & $4.420 \pm 1.380$ & NS \\
R. albus $\left(\times 10^{5} / \mathrm{ml}\right)$ & $1.910 \pm 0.667^{\mathrm{b}}$ & $1.330 \pm 0.301^{\mathrm{b}}$ & $11.50 \pm 1.690^{\mathrm{a}}$ & $4.390 \pm 1.220^{\mathrm{ab}}$ & $*$ \\
R. flavefaciens $\left(\times 10^{8} / \mathrm{ml}\right)$ & $2.240 \pm 0.401$ & $7.180 \pm 2.850$ & $6.050 \pm 1.280$ & $3.330 \pm 0.613$ & NS \\
\hline
\end{tabular}

CNT: basal diet; OL: basal diet + olive oil diet; PO: basal diet + alm olein; SF: basal diet + sunflower oil diet; Sig: Signifinatcy; "Significant level at P<0.05; NS: not significant; ${ }^{\text {ab } M e a n s ~} \pm$ std error in the same row with different superscripts are statistically different $(\mathrm{P}<0.05)$

\section{CONCLUSION}

The population of predominant rumen fibre-degrading bacteria was remarkably increased by the supplementation of olive oil, palm olein oil and sunflower oil. Population of $F$. succinogens was increased by supplementation of olive oil, $R$. albus was increased by supplementation of palm olein oil and sunflower oil and population of $R$. flavefaciens was increased by supplementation of all three oils suggested that supplementation of these three different oils could develop better rumen microorganism populations in goats. This will benefit the animals by providing extra energy from the dietary oil supplementation without compromising the ability in the rumen fibre digestion process.

\section{ACKNOWLEDGEMENT}

This research was funded by RUGS (9199720) awarded by Universiti Putra Malaysia. A. Ibrahim was a recipient of MyBrain15 Scholarship from the Malaysia Ministry of Higher Education.

\section{REFERENCES}

Denman SE, McSweeney CS. 2006. Development of a real-time PCR assay for monitoring anaerobic fungal and cellulolytic bacterial populations within the rumen. FEMS Microbiol. Ecol. 58:572-582. 
Ivan M, Petit HV, Chiquette J, Wright AD. 2013. Rumen fermentation and microbial population in lactating dairy cows receiving diets containing oilseeds rich in C-18 fatty acids. Bri J Nutr. 109:1211-1218.

Koike S, Kobayashi Y. 2001. Development and use of competitive PCR assays for the rumen cellulolytic bacteria: Fibrobacter succinogenes, Ruminococcus albus and Ruminococcus flavefaciens. FEMS Microbiol Lett. 204:361-366.

Navidshad B, Liang JB, Jahromi MF. 2012. Correlation coefficients between different method of expressing bacterial quantification using Real Time PCR. Intl J Mol Sci. 13:2119-2132.

NRC. 1981. Nutrient requirements of goats. Washington DC (USA): National Academy Press.

Samsudin AA, Wright ADG, Al Jassim RAM. 2014. The effect of fibre source on the numbers of some fibre degrading bacteria of Arabian camel's (Camelus dromedaries) foregut origin. Trop. Anim. Health Prod. 46:1161-1166.

Wanapat M, Pilajun R. 2011. Effect of coconut oil and mangosteen peel supplementation on ruminal fermentation, microbial population, and microbial protein synthesis in swamp buffaloes. Livest Sci. 141:148-154.

Yabuuchi Y, Tani M, Matsushita Y, Otsuka H, Kobayashi Y. 2007. Effects of lauric acid on physical, chemical and microbial characteristics in the rumen of steers on a high grain diet. Anim Sci J. 78:387-394. 